\title{
Blood-Borne Angiotensin II Acts in the Brain to Influence Behavioral and Endocrine Responses to Psychogenic Stress
}

\author{
Eric G. Krause, ${ }^{1}$ Annette D. de Kloet, ${ }^{2}$ Karen A. Scott, ${ }^{3,5}$ Jonathan N. Flak, ${ }^{3,5}$ Kenneth Jones, ${ }^{3}$ Michael D. Smeltzer, ${ }^{3}$ \\ Yvonne M. Ulrich-Lai, ${ }^{3}$ Stephen C. Woods, ${ }^{3}$ Steven P. Wilson, ${ }^{4}$ Lawrence P. Reagan, ${ }^{4}$ James P. Herman, ${ }^{3}$ \\ and Randall R. Sakai ${ }^{3}$ \\ ${ }^{1}$ Department of Pharmacodynamics, College of Pharmacy, and ${ }^{2}$ Department of Physiology and Functional Genomics, College of Medicine, University of \\ Florida, Gainesville, Florida 32610, ${ }^{3}$ Department of Psychiatry and Behavioral Neuroscience, University of Cincinnati, College of Medicine, Cincinnati, Ohio \\ 45221, ${ }^{4}$ Department of Pharmacology, Physiology, and Neuroscience, School of Medicine, University of South Carolina, Columbia, South Carolina 29208, \\ and ${ }^{5}$ Neuroscience Graduate Program, College of Medicine, University of Cincinnati, Cincinnati, Ohio 45267
}

This study elucidates the neural circuits by which circulating angiotensin II (ANGII) acts in the brain to influence humoral and behavioral responses to psychological stressors. To test the hypothesis that systemic ANGII mediates stress responding via the subfornical organ (SFO), we first found that the timing of increased systemic ANGII in response to $60 \mathrm{~min}$ restraint coincides with increased $c$-fos mRNA expression in the SFO. Next, we administered an anterograde neuronal tract tracer into the SFO and found that fibers originating there make appositions onto neurons in the paraventricular nucleus of the hypothalamus that are also $c$-fos positive following restraint stress. To determine whether circulating ANGII stimulates the release of stress hormones via activation of angiotensin type 1 receptors (AT1R) within the SFO, we delivered lentivirus to knockdown AT1R expression locally in the SFO. Inhibition of AT1R specifically within the SFO blunted the release of adrenocorticotrophin-releasing hormone and corticosterone in response to restraint stress and caused rats to spend more time in the open arms of an elevated-plus maze than controls, indicating that inhibition of AT1R within the SFO is anxiolytic. Collectively, these results suggest that circulating ANGII acts on AT1R in the SFO to influence responding to psychological stressors.

\section{Introduction}

Accumulating evidence suggests that stressful life events initiate the pathogenesis of depression and anxiety disorders, which predicts the onset and severity of cardiovascular disease (CVD) (Sowden and Huffman, 2009; Carroll et al., 2010; Garcia-Vera et al., 2010; Stein et al., 2010). Hypertension, another predictor of $\mathrm{CVD}$, is associated with elevated circulating angiotensin II (ANGII), which exerts its effects by stimulating angiotensin type 1 receptors (AT1Rs). The synthesis of ANGII is dependent on angiotensin converting enzyme (ACE), and polymorphisms in the ACE gene are also predictive of depression and anxiety disorders (Baghai et al., 2002, 2006; Angunsri et al., 2009). These polymorphisms increase ACE activity and are accompanied by elevated ANGII and overactivation of the hypothalamicpituitary-adrenal (HPA) axis (Rigat et al., 1990, Baghai et al., 2002 , 2006), a neuroendocrine abnormality in patients with affective disorder (Holsboer and Barden, 1996). Interestingly, in-

Received Feb. 18, 2011; revised Aug. 25, 2011; accepted Aug. 26, 2011.

Author contributions: E.G.K., A.D.d.K., Y.M.U.-L., S.C.W., J.P.H., and R.R.S. designed research; E.G.K., A.D.d.K., K.A.S., J.N.F., K.J., M.D.S., and R.R.S. performed research; E.G.K., S.P.W., and L.P.R. contributed unpublished reagents/analytic tools; E.G.K. and A.D.d.K. analyzed data; E.G.K., S.C.W., and J.P.H. wrote the paper.

This work was supported by National Institutes of Health (NIH) Grant HL096830 (E.G.K.), American Heart Association Grant 09PRE2250169 and NIH Grant F31 NS068122 (A.D.d.K.), NIH Grant MH49698 (J.P.H.), and NIH Grants DK66596-05A2S1 and DK66596 (R.R.S.).

The authors have no conflicts of interest.

Correspondence should be addressed to Dr. Eric G. Krause at the above address. E-mail: ekrause@cop.ufl.edu. DOI:10.1523/JNEUROSCI.0892-11.2011

Copyright $\odot 2011$ the authors $\quad 0270-6474 / 11 / 3115009-07 \$ 15.00 / 0$ hibition of AT1R normalizes HPA dysfunction and improves affect, suggesting that stimulation of AT1R drives HPA activation and influences mood (Pavlatou et al., 2008).

While it is clear that elevated circulating ANGII is associated with increased HPA activity and susceptibility to psychopathology, the central mechanism(s) underlying the influence of ANGII on mood and HPA responsiveness is unknown. Mood and HPA responding are regulated by the CNS, which is isolated from systemic circulation by the blood-brain barrier. One exception to this is the subfornical organ (SFO), a brain region with a relaxed blood-brain barrier that expresses AT1R and responds to circulating ANGII (McKinley et al., 2003). The SFO has direct angiotensinergic projections to the dorsal raphe nucleus (DRN) (Lind, 1986; Tanaka et al., 1998) and paraventricular nucleus (PVN) of the hypothalamus (Miselis, 1981; Swanson and Lind, 1986; Li and Ferguson, 1993), brain regions implicated in the control of mood and HPA activation, respectively. Consequently, the SFO is a prime candidate for the site where systemic ANGII facilitates the development of psychopathology and HPA dysregulation.

The present experiments used a rat model to test the hypothesis that psychological stress elevates systemic ANGII, which acts on receptors in the SFO to influence mood and stress responding. We first examined plasma rennin activity (PRA), a surrogate indicator of circulating ANGII, during physical restraint. We then systemically administered an AT1R antagonist and measured postrestraint $c$-fos mRNA expression to determine whether increased circulating ANGII activated SFO neurons. Next, we injected an anterograde neuronal tract tracer into the SFO to 
ascertain whether fibers originating there make direct appositions onto neurons in the PVN that are activated during restraint. To determine whether circulating ANGII stimulates the release of stress hormones via activation of AT1R within the SFO, we delivered lentivirus to knockdown AT1R expression locally into the SFO and measured HPA activation during restraint. To test whether knockdown of AT1R in the SFO influences mood, we assessed anxiety-like behavior in rats administered lentivirus into the SFO. The results demonstrate that psychological stress elevates circulating ANGII, which then acts on AT1R in the SFO to increase HPA responding and anxiety-like behavior.

\section{Materials and Methods}

Animals. Adult male Sprague Dawley rats (Harlan) weighing 250-300 g at the initiation of the study were used. Rats arrived at least 2 weeks before the onset of the experiment and were individually housed on a $12 \mathrm{hlight}$, $12 \mathrm{~h}$ dark cycle $(0600-1800 \mathrm{~h})$ with ad libitum access to pelleted rat chow and water. All procedures were approved by the University of Cincinnati Institutional Animal Care and Use Committee, Cincinnati, $\mathrm{OH}$.

Trunk blood sampling for analysis of plasma hormones. Rats were sacrificed and morning trunk blood samples were taken to measure basal levels of PRA, adrenocorticotrophin-releasing hormone (ACTH), and corticosterone (CORT). Another cohort of rats was placed into plastic restrainers and trunk blood samples were collected 7.5, 15, 30, and 60 $\mathrm{min}$ after the onset of restraint. One subset of rats underwent $60 \mathrm{~min}$ restraint but was released and then sacrificed $1 \mathrm{~h}$ later for the $120 \mathrm{~min}$ recovery time point. Trunk blood samples were collected in chilled tubes containing EDTA and centrifuged at $3500 \mathrm{rpm}$. Plasma was stored at $-80^{\circ} \mathrm{C}$ until analysis for hormones via radioimmunoassay (RIA).

In situ hybridization. Antisense cRNA probes complementary to c-fos (594 bp) were generated by in vitro transcription using ${ }^{35} \mathrm{~S}$-uridine 5-triphosphate. The $c$-fos fragment (original full-length cDNA from T. Curran, St. Jude Children's Research Hospital, Memphis, TN) was cloned into a TOPO PCR vector (Invitrogen), linearized with HindIII, and transcribed with T3 RNA polymerase. Pretreatment of slides, hybridization, posttreatment, and image analysis were performed as described previously (Krause et al., 2006).

Real-time polymerase reaction. Rats were administered losartan (40 $\mathrm{mg} / \mathrm{kg}$ s.c.; U.S. Pharmacopeia) and $30 \mathrm{~min}$ later were placed into plastic restrainers. Forty-five minutes after the onset of restraint, rats were sacrificed and extracted brains were flash frozen in dry ice-cooled 2-methylbutane and stored at $-80^{\circ} \mathrm{C}$ until dissection of the SFO. Briefly, brains were acclimated to $-12^{\circ} \mathrm{C}$ and blocked at the rostral $(-0.8 \mathrm{~mm})$ and caudal $(-1.40 \mathrm{~mm}$ ) boundaries of the SFO (Paxinos and Watson, 1997). Thick sections were laid on a freezing stage and punches of the SFO were taken and submerged in RNA later (Ambion) until RNA extraction.

On the day of RNA extraction, SFO punches were homogenized in 350 $\mu \mathrm{l}$ of Buffer RLT (Qiagen) using a TissueLyser (Qiagen). RNA was then extracted from the SFO punches using Qiagen RNAeasy columns according to the manufacturer's instructions (Qiagen). DNAase treatment (Qiagen) was performed to minimize genomic DNA contamination of RNA extracts. Subsequently, iScript (Bio-Rad) was used to synthesize cDNA from $0.5 \mu \mathrm{g}$ total RNA. Gene expression analysis of diluted cDNA (1:2) samples was run in duplicate using a 7900HT Fast Real-Time PCR system, TaqMan Gene Expression Master Mix, and validated TaqMan probes (Applied Biosystems). The expression of c-fos (Assay ID: Rn02396760_g1) was normalized to constitutively expressed ribosomal protein L32 (Assay ID: Rn00820748_g1), and relative expression was quantified using the $2^{\Delta \Delta \mathrm{Ct}}$ method.

Phaeseolus vulgairs leucoagglutinin administration and immunohistochemistry. Anterograde tracer was injected into the SFO and triple-label immunohistochemistry was performed to evaluate the phenotype of neurons within the PVN that receive direct projections from neurons in the SFO. Rats received stereotaxic microiontophoretic injections of $P$ haeseolus vulgairs leucoagglutinin (PHA-L) (2.5\% PHA-L in 10 mM PBS; 6 $\mu \mathrm{A}, 7 \mathrm{~s}$ pulses, $20 \mathrm{~min}$ ) into the SFO using the following coordinates from bregma: $11^{\circ}$ angle from the vertical plane, anterior $1.3 \mathrm{~mm}$, lateral 1.0 $\mathrm{mm}$, and ventral $5.1 \mathrm{~mm}$ from dura. Missed injections served as controls for anatomical specificity, contrasting projections of neighboring regions from the targeted areas themselves. Ten days postsurgery, animals were restrained for $60 \mathrm{~min}$ and released, and $60 \mathrm{~min}$ later were deeply anesthetized with pentobarbital and perfused with $4 \%$ paraformaldehyde. Collected brains were sectioned on a sliding microtome at $30 \mu \mathrm{m}$ thickness. Triple immunostaining for human neuronal-specific protein at 1:5000 (mouse anti-HuC/D; Invitrogen), Fos protein at 1:3000 (rabbit anti-Fos; Santa Cruz Biotechnology), and PHA-L at 1:3000 (goat-antiPHA-L; Vector Laboratories) were performed. Briefly, sections were rinsed in $50 \mathrm{~mm} \mathrm{~K}-\mathrm{PBS}$, underwent $30 \mathrm{~min}$ antigen retrieval, were blocked in $1 \%$ BSA with $0.1 \%$ Triton-X for $1 \mathrm{~h}$, and then incubated in primary antibodies overnight. The next day, sections were rinsed in 50 mM K-PBS and incubated in secondary antibodies at 1:500 for $1 \mathrm{~h}$ (Cy3 anti-mouse, Cy5 anti-rabbit, Alexa Fluor 488 anti-goat; Jackson ImmunoResearch Laboratories). Finally, sections were rinsed in $50 \mathrm{~mm}$ K-PBS, mounted onto microscope slides, and coverslipped. All injections were verified on counterstained sections with reference to known cytoarchitectural landmarks. Injection sites were verified by the presence of PHA-L immunoreactivity within the SFO without spreading to surrounding brain nuclei. Missed injections were found to terminate in the fornical commissure or lateral ventricle and did not produce a label of efferent fibers. Images were obtained using a Zeiss ApoTome microscope system and deconvolution package. Appositions between PHA-L nerve terminals and Fos/HuCD-containing neurons were assessed in $0.5 \mu \mathrm{m}$ sections through the PVN. Appositions were verified by lack of separation between boutons (green) and cells (red) in any sequence of optical sections. For presentation purposes, images were adjusted for brightness and contrast using Adobe Photoshop.

Stereotaxic surgery. Rats were anesthetized under ketamine $\mathrm{HCl}$ (100 $\mathrm{mg} / \mathrm{kg}$ body wt, i.p.; Bristol Laboratories $)$ and acepromazine $(1.37 \mathrm{mg} / \mathrm{kg}$ body wt, i.p.; Ayerst Laboratories); subsequently, 26 gauge microinjection cannulas (Plastics One) were stereotaxically implanted in the SFO. The stereotaxic coordinates from bregma, using a $10^{\circ}$ lateral angle from the vertical plane, were as follows: anterior $1.2 \mathrm{~mm}$, lateral $1.0 \mathrm{~mm}$, and ventral $5.6 \mathrm{~mm}$ from skull. We have previously found that these coordinates consistently target the SFO without causing damage to it or surrounding structures (Krause et al., 2008). Ten days of recovery was allowed for body weight to return to presurgical levels before lentivirus was administered.

Lentivirus construction and administration. A plasmid containing the full-length cDNA of the rat AT1R gene was generously provided by J.K. Harrison (University of Florida, Gainesville, FL). This DNA fragment was cloned into a lentivirus transfer vector (LV-AS), inserted in antisense orientation relative to the human phosphoglycerate kinase-1 (PGK) promoter. This transfer vector also contained an encephalomyocarditis virus internal ribosome entry site (IRES), DNA encoding the enhanced green fluorescent protein (GFP), and the woodchuck hepatitis virus posttranscription regulatory element, WPRE). Virus was produced by transfection of human embryonic kidney 293T cells with the transfer vector packaging plasmid (pCMV $\Delta$ R8.92), a plasmid encoding the rev gene, and a plasmid encoding vesicular stomatitis virus $\mathrm{G}$ glycoprotein gene. The viruses were concentrated by centrifugation, resuspended in $10 \%$ sucrose $/ \mathrm{PBS}$, and stored at $-80^{\circ} \mathrm{C}$. Virus concentrations were $25-30 \mu \mathrm{g}$ of p24 per ml. A control virus, LV-GFP, was constructed similarly, using a transfer vector with the PGK promoter driving expression of GFP alone (no IRES). The control virus was selected based on studies determining that ANGII binding to AT1R was similar when LV-GFP or lentivirusexpressing GFP and the product of the scrambled DNA fragment were administered (data not shown). After recovery from surgery, rats were anesthetized under isoflurane and were injected $(0.5 \mu \mathrm{l} / \mathrm{min}$ over $2 \mathrm{~min})$ with LV-GFP or LV-AS into the SFO. After administration of lentivirus, the internal cannula remained in place for an additional $15 \mathrm{~min}$. Preliminary studies found that virus efficacy was maximal 5-6 weeks after administration and, consequently, experimental testing began at this time.

Tail blood sampling for analysis of the HPA response. Morning tail blood samples $(250-300 \mu \mathrm{l})$ were gently taken from rats administered LV-GFP or LV-AS to determine basal levels of ACTH and CORT. Subsequently, rats were placed into plastic restrainers and tail blood samples were col- 

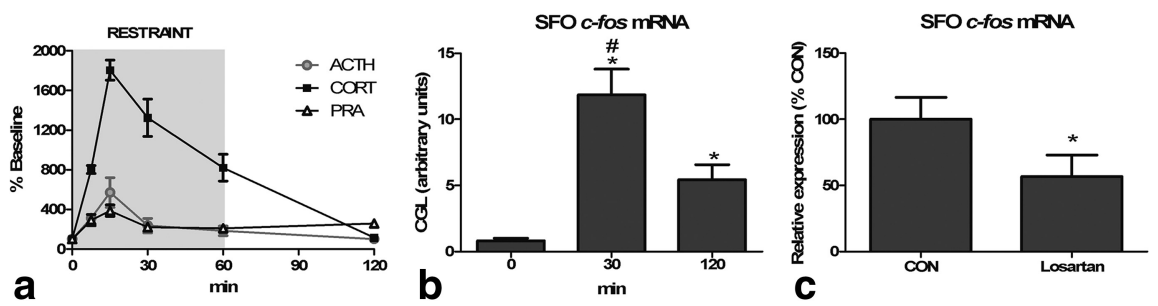

Figure 1. $\quad \boldsymbol{a}$, Sixty-minute restraint elicits elevations in ACTH, CORT, and PRA with similar peaks at $15 \mathrm{~min}(n=8$ per group and time point). $\boldsymbol{b}$, Restraint significantly increases c-fos mRNA in the SFO [asterisk $\left({ }^{*}\right)$, different than 0 min; pound sign (\#), different than $120 \mathrm{~min}^{*}{ }^{*}, p<0.05, n=8$ per group). c, Restraint-induced c-fos mRNA expression in the SFO is attenuated by systemic pretreatment with losartan $\left({ }^{*} p<0.05, n=6\right.$ per group).

lected 15, 30, and $60 \mathrm{~min}$ after the onset of restraint. After the $60 \mathrm{~min}$ sample, rats were released and another sample was taken at the $120 \mathrm{~min}$ recovery time point. Blood samples were collected in chilled tubes containing EDTA and centrifuged at $3500 \mathrm{rpm}$. Plasma was stored at $-80^{\circ} \mathrm{C}$ until analysis for hormones via RIA.

Radioimmunoassay. Plasma renin activity was measured by RIA using a ${ }^{125} \mathrm{I}$ kit from DiaSorin. Plasma ACTH was measured by RIA using an antiserum donated by Dr. William Engeland (University of Minnesota, Minneapolis, MN) and ${ }^{125} \mathrm{I}-\mathrm{ACTH}$ as tracer (GE Healthcare). Plasma CORT was measure by RIA using a ${ }^{125} \mathrm{I}$ kit from MP Biomedicals.

Histological verification. Brains were removed and sectioned, and cannula placement was evaluated. If the tract of the guide cannula was not adjacent to the SFO, caused damage to it or surrounding nuclei, or if GFP was observed in nuclei other than the SFO, then the subject was excluded from the study.

Quantification of AT1R knockdown. Receptor autoradiography was used to assess the efficacy of lentiviral knockdown of AT1R expression. Autoradiographic measurement of ANGII binding to AT1R in the SFO and PVN was performed as described previously (Krause et al., 2008). Adjacent sections were mounted onto slides and imaged for the reporter gene, GFP, or immunostained for neuronal-specific nuclear protein (NeuN) to determine the viability of neurons infected with the lentivirus. Immunohistochemistry for NeuN was performed as described previously (Solomon et al., 2010).

Assessment of anxiety-like behavior. Elevated-plus-maze (EPM) experiments were performed 2 weeks after the restraint stress test, and each rat was tested only once. The black Plexiglas EPM consisted of two opposing open $(56 \times 10 \times 0.5 \mathrm{~cm})$ and two closed $(56 \times 10 \times 40 \mathrm{~cm})$ arms elevated $50 \mathrm{~cm}$ above the floor and had a $0.5 \mathrm{~cm}$ edge on the open arms. The floor was a gray Plexiglas to accommodate the automated scoring using contrast analysis. Animals were placed in the center square facing an open arm and allowed to explore the maze for $5 \mathrm{~min}$. EPM tests were conducted under dim illumination during the light phase. The maze was cleaned with a $5 \%$ ammonium hydroxide solution between subjects. During EPM testing, each rat's behavior was videotaped from overhead, and a computerized tracking system (TopScan, CleverSys) was used to measure time spent in each arm of the EPM and the total distance traveled.

Statistical analysis. Data were analyzed using Statistica (StatSoft). All data are expressed as means \pm SEM. Angiotensin II binding was analyzed using a one-factor ANOVA with treatment (LV-AS or LV-GFP) as the factor. Trunk bloods collected for PRA, ACTH, and CORT were analyzed using a one-factor ANOVA with time as the factor. Studies using in situ hybridization to measure c-fos mRNA were analyzed using a 1-factor ANOVA with time as the factor. Plasma levels of CORT and ACTH were assessed using two-factor repeated-measures ANOVA with treatment (LV-AS or LV-GFP) and time as the factors. Pearson R correlation was used to describe the relationship between ANGII binding to AT1R in the SFO and restraint-induced ACTH and CORT at 15 and $30 \mathrm{~min}$, respectively. Time spent on the open arms of the EPM, total distance traveled, and $c$-fos mRNA from RT-PCR were analyzed with a one-tailed $t$ test. Main effects or interactions $(p<0.05)$ were assessed with Student and Newman-Keuls tests.

\section{Results \\ Restraint-induced elevations in PRA parallel those of ACTH and CORT and are commensurate with activation of SFO neurons}

To characterize the time course of ANGII synthesis during psychological stress, we measured PRA, ACTH, and CORT before, during, and $60 \mathrm{~min}$ after the cessation of physical restraint. As shown in Figure $1 a$, restraint significantly elevated $\left.\operatorname{ACTH}\left(F_{(1,5}\right)=5.83 ; p<0.001\right)$, CORT $\left.\left(F_{(1,5}\right)=40.8 ; p<0.001\right)$, and PRA $\left.\left(F_{(1,5}\right)=6.25 ; p<0.001\right)$ above basal levels $($ PRA $=15.6 \pm 1.91 \mathrm{ng} / \mathrm{ml} / \mathrm{h} ; \mathrm{ACTH}=$ $36.6 \pm 11.5 \mathrm{pg} / \mathrm{ml} ;$ CORT $=60.8 \pm 22.6 \mathrm{ng} / \mathrm{ml})$. Specifically, ACTH was significantly $(p<0.05)$ elevated at 7.5 and $15 \mathrm{~min}$ and returned to baseline at $30 \mathrm{~min}$. Corticosterone was significantly $(p<0.05)$ elevated at 7.5, 15, 30, and $60 \mathrm{~min}$ and returned to baseline at $120 \mathrm{~min}$. Interestingly, psychological stress significantly $(p<0.05)$ increased PRA, indicative of elevated ANGII, at all poststress time points and peak levels corresponded to those of ACTH and CORT. To determine whether the increased circulating ANGII is commensurate with activation of SFO neurons, we examined poststress $c$-fos mRNA expression and found a significant $\left.\left(F_{(1,2}\right)=17.9 ; p<0.001\right)$ increase above basal levels 30 and 120 min after the onset of restraint (Fig. 1b). Next, we administered an AT1 receptor antagonist or the saline vehicle and subsequently examined poststress $c$-fos mRNA expression in the SFO. As depicted in Figure 1c, systemic administration of losartan significantly $(p<0.05)$ decreased restraint-induced $c$-fos mRNA expression within the SFO, consistent with ANGII-induced activation (Cullinan et al., 1995). These results suggest that psychological stress increases circulating ANGII, which activates neurons within the SFO.

\section{Neurons within the PVN that are activated during restraint receive direct projections from the SFO}

To evaluate the central pathways mediating the influence of ANGII on the HPA axis, we administered an anterograde neuronal tract tracer into the SFO, and these rats subsequently underwent restraint stress. Consistent with another study, the efferent projections that were observed were dependent on the subregion of SFO neurons that were delivered PHA-L (Kawano and Masuko, 2010). Injections into the lateral-peripheral region of the SFO (Fig. 2b,c) produced scant anterograde label within both the magnocellular and parvocellular subdivisions of the PVN. Injections into the ventromedial core of the SFO (Fig. 2d) resulted in robust label of anterograde fibers that were mostly localized within the medial parvocellular subdivision of the PVN. SFO-originating fibers made contact with neurons in the anterior and medial parvocellular division of the PVN that were c-fos positive following restraint stress (Fig. 3). The frequency of these contacts was also dependent on the subregion of the SFO neurons that were delivered PHA-L. In subjects $(n=2)$ that had uptake of PHA-L restricted to the lateral-peripheral region of the SFO (Fig. $2 b, c)$ a total of five triple-labeled neurons were found within the anterior and medial parvocellular region of the PVN (Fig. 3a,c). However, a total of 18 triple-labeled neurons within the medial parvocellular region of the PVN (Fig. 3b,d) were found when the subject had uptake of PHA-L within the ventromedial core of the SFO (Fig. $2 d$ ). These data demonstrate that fibers from the SFO 
project directly onto PVN neurons that are activated in response to psychological stress.

\section{Lentiviral knockdown of AT1R in the SFO attenuates HPA responding to} restraint stress and decreases anxietylike behavior

We delivered lentivirus to knockdown AT1R expression locally in the SFO to investigate whether circulating ANGII excites the HPA axis via activation of AT1R. Rats administered lentivirus into the SFO express the reporter gene GFP within this nucleus (Fig. 4a, upper left). Adjacent sections through the SFO of rats administered lentivirus express $\mathrm{NeuN}$, indicating that neurons infected with lentivirus remain viable (Fig. $4 a$, top right). To evaluate the efficacy of lentiviral knockdown of AT1R, we performed receptor autoradiography to measure ANGII binding in the SFO and PVN. Rats administered LV-AS had significantly less $\left(F_{(1,15}\right)=$ $68.4 ; p<0.05)$ ANGII binding to AT1R in the SFO when compared to that of LVGFP-treated controls (Figs. $4 a$, bottom left and right, $b$ ). Importantly, ANGII binding in the PVN, a nucleus proximal to the SFO that also expresses AT1R, was similar $\left.\left(F_{(1,8}\right)=0.23 ; p=0.64\right]$ in rats given LV-AS and LV-GFP (Fig. $4 b$ ). Rats administered LV-AS or LV-GFP into the SFO underwent $60 \mathrm{~min}$ restraint to evaluate the effect of AT1R inhibition on HPA responding and a time $\times$ condition interaction was found (ACTH: $\left.F_{(1,4}\right)=3.02$, $p<0.05$; CORT: $\left.F_{(1,4)}=5.36, p<0.05\right)$. Post hoc analyses revealed that inhibition of AT1R specifically within the SFO significantly decreased $(p<0.05)$ the release of ACTH and CORT at 15 and $30 \mathrm{~min}$, respectively (Fig. 5a,b). Interestingly, decreased AT1R binding in the SFO was correlated with attenuated ACTH $(r=0.648)$ and CORT $(r=0.344)$ at $15 \mathrm{~min}$ and 30 min, respectively. Attenuated release of ACTH and CORT during restraint predicts altered behavioral responses to psychological stress exposure. To test this prediction, we used the EPM to assess anxiety-like behavior and found that LV-AS rats spent significantly more $(p<$ $0.05)$ time in the open arms of the EPM than LV-GFP controls, but total distance traveled was similar (Fig. $5 c, d$ ). In combination, the data are consistent with attenuation of anxiety responses by AT1R knockdown.

\section{Discussion}

The current study provides novel evidence for peripheral drive of neuroendocrine and behavioral stress responses by
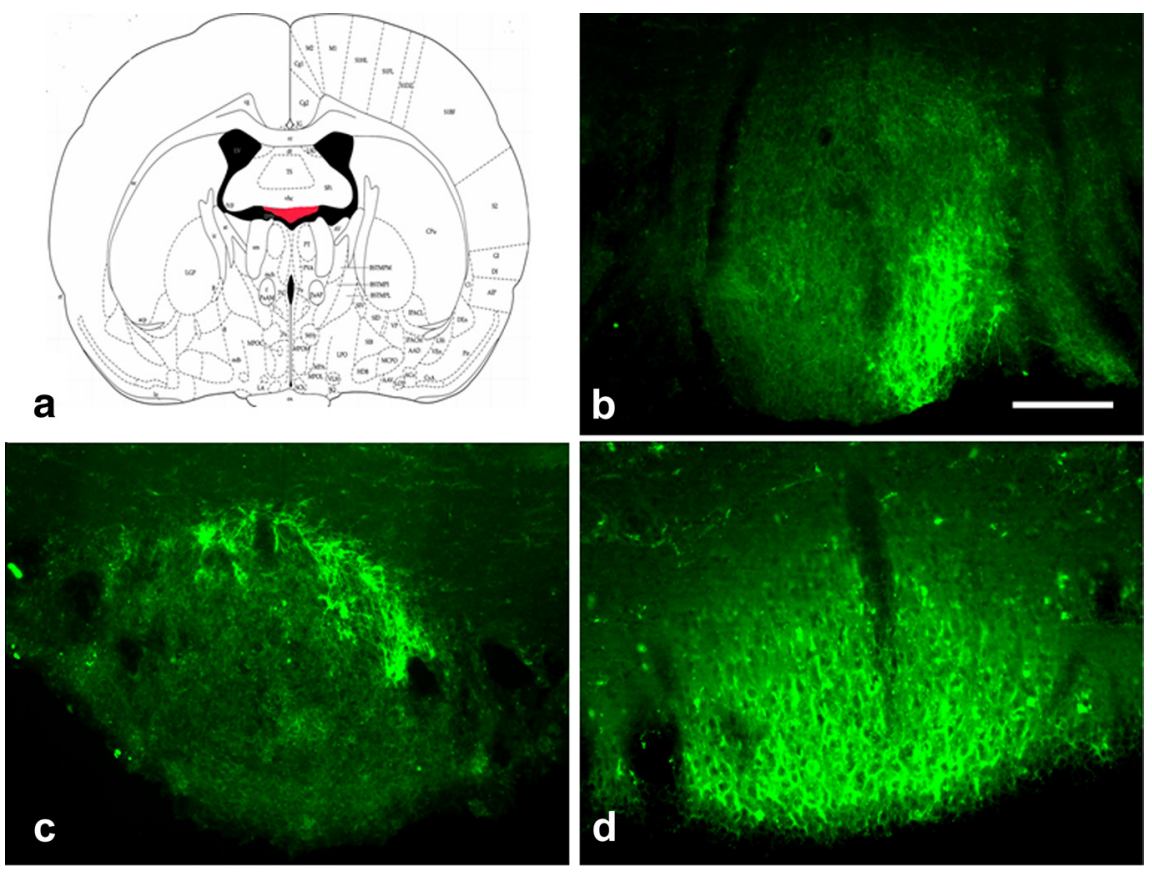

Figure 2. $\boldsymbol{a}$, Drawing of coronal section through the SFO highlighted in red. $\boldsymbol{b}-\boldsymbol{d}$, Representative cases of rats administered PHA-L into the SFO (green, Alexa Fluor 488, PHA-L-positive fibers). Scale bars, $250 \mu \mathrm{m}$ ).
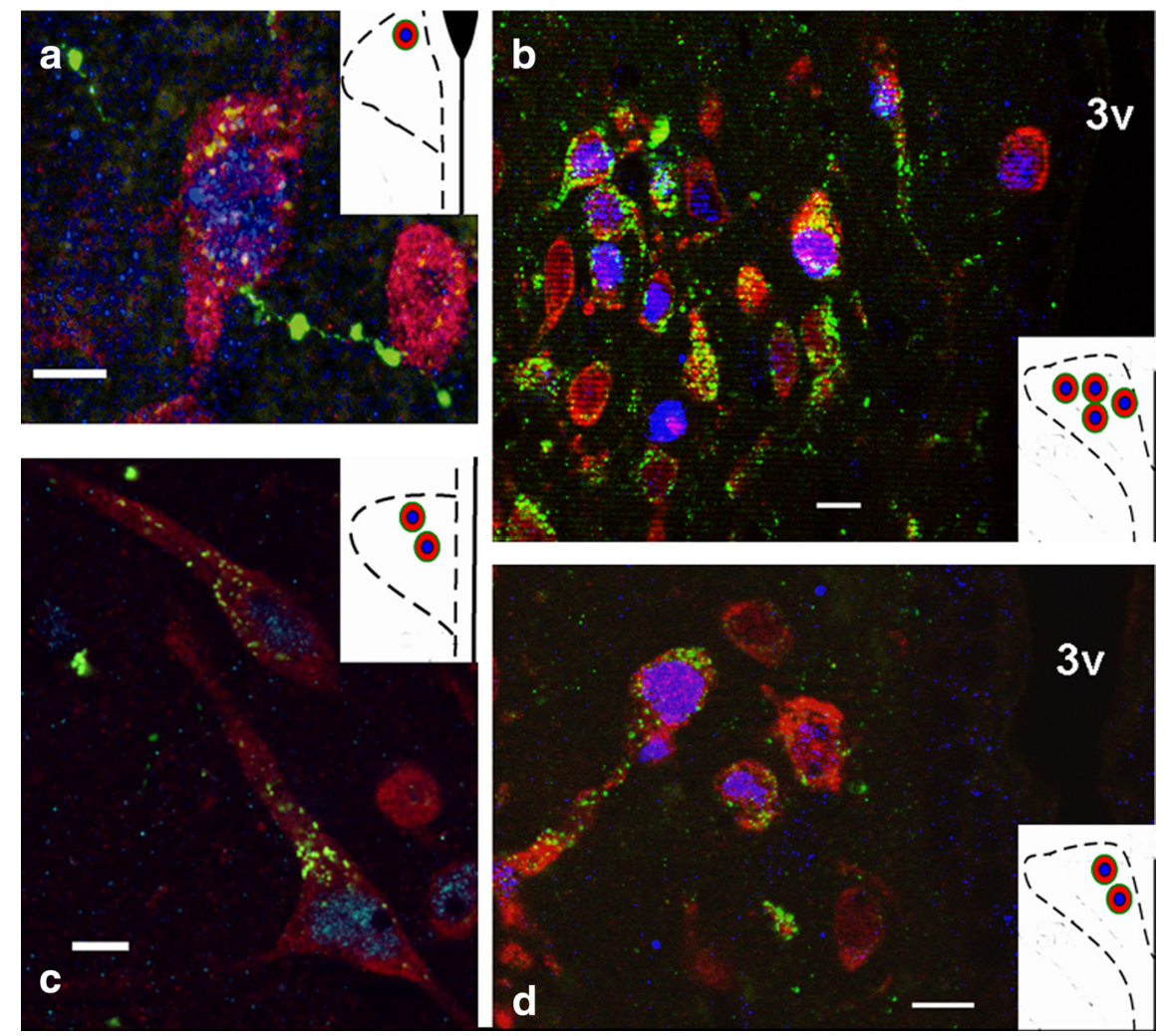

Figure 3. (a) High-magnification image of a neuron in the anterior parvocellular PVN that is activated during restraint and receives direct efferent projections from the SF0; efferent fibers result from injection site shown in Figure 2c. Scale bar, $25 \mu \mathrm{m} . \boldsymbol{b}$, Lower-magnification image of neurons in the medial parvocellular PVN that are activated during restraint and receive direct projections from the SFO; efferent fibers result from injection site shown in Figure 2d. Scale bar, $50 \mu \mathrm{m}$. c, High-magnification image of neurons in the anterior/medial parvocellular PVN that are activated during restraint and receive direct projections from the SF0; efferent fibers result from injection site shown in Figure $2 b$. Scale bar, $25 \mu \mathrm{m}$. $\boldsymbol{d}$, Lower-magnification image of neurons in the medial parvocellular PVN that are activated during restraint and receive direct projections from the SF0; efferent fibers result from injection site shown in Figure $2 \mathrm{~d}$. Scale bar, $50 \mu \mathrm{m}$. Insets, Drawings of unilateral coronal sections through the anterior or medial parvocellular PVN depicting the location of the triple labeled neurons (red, Cy3-positive label for HuCD; blue, Cy5 c-fospositive nuclei; green, Alexa Fluor 488 PHA-L fibers from SF0). 


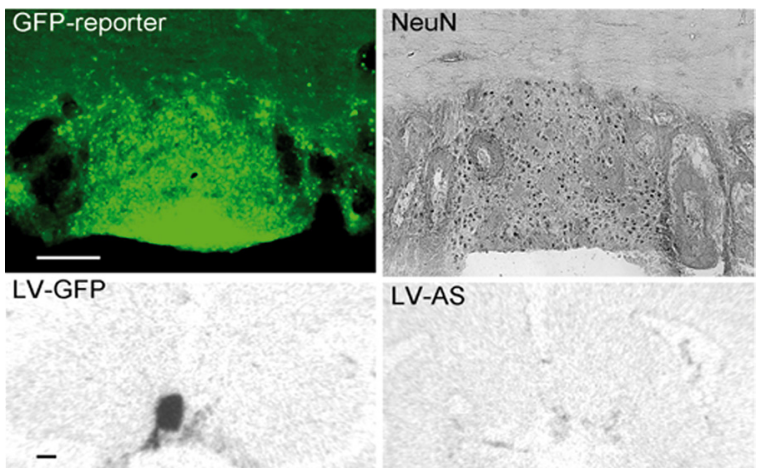

a

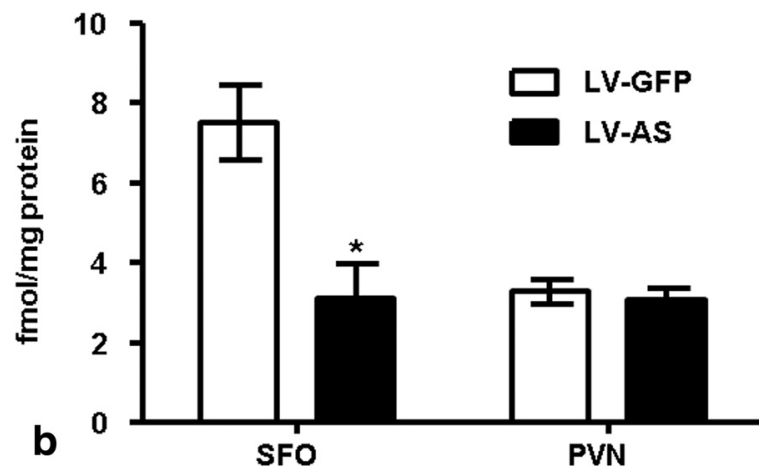

Figure 4. $\quad \boldsymbol{a}$, Representative coronal sections through the SFO from rats administered lentivirus. Top left, Neurons within the SF0 express GFP. Top right, Adjacent section stained for NeuN. Scale bar, $250 \mu \mathrm{m}$. Bottom left, Autoradiograph indicative of ANGII binding in the SFO of rats administered LV-GFP. Bottom right, Autoradiograph indicative of ANGII binding in the SFO of rats administered LV-AS. Scale bar, $1 \mathrm{~mm}$. $\boldsymbol{b}$, Receptor autoradiography indicative of ANGII binding in the SFO and PVN. Administration of LV-AS significantly decreases ( ${ }^{*} p<0.05$ ) ANGII binding in the SFO but has no effect on the PVN (LV-GFP SF0, $n=8$; LV-AS SF0, $n=8$; LV-GFP PVN, $n=5$; LV-ASPVN, $n=5$ ).
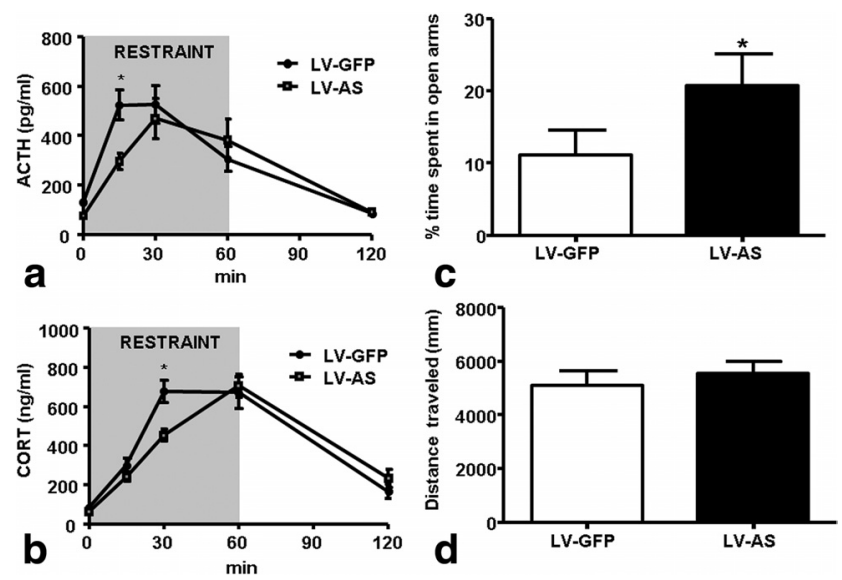

Figure 5. $\boldsymbol{a}, \boldsymbol{b}$, Administration of LV-AS into the SFO significantly decreases $\left({ }^{*} p<0.05\right)$ the release of ACTH (a) and CORT (b) during restraint (ACTH LV-GFP, $n=12$; ACTH LV-AS, $n=12$; CORT LV-GFP, $n=16$; CORT LV-AS, $n=15$ ). $\boldsymbol{c}$, $\boldsymbol{d}$, Delivery of LV-AS into the SF0 significantly increases $\left({ }^{*} p<0.05\right)$ the amount of time spent in the open arms of the EPM but has no effect on total distance traveled ( $n=12$ per group).

the action of ANGII at the SFO. Exposure to acute psychological stress increased PRA, an indicator of circulating ANGII, on a time course parallel to that of ACTH and CORT, identifying ANGII as a "stress hormone." The elevations in PRA during restraint were commensurate with increased expression of $c$-fos mRNA in the $\mathrm{SFO}$, indicative of increased neuronal activity in this brain region
(Dragunow and Faull, 1989; Cullinan et al., 1995). Moreover, SFO fibers make direct appositions onto neurons in the PVN that were activated by restraint stress, suggesting that systemic ANGII indirectly affects the activity of PVN neurons by means of projections from the SFO. Supporting this hypothesis, lentiviral knockdown of AT1R specifically within the SFO attenuated HPA responding during restraint stress. Attenuated HPA responding during stress predicts decreased anxiety-like behavior, and indeed rats administered LV-AS into the SFO spent more time in the open arms of the EPM when compared to controls. The data identify a novel mechanism whereby peripheral hormones and peptides can have powerful effects on central stress processing and behavior without directly accessing the brain parenchyma.

Angiotensin II is best known for its regulatory role in body fluid homeostasis (for review, see Krause and Sakai, 2007); however, during restraint stress PRA was elevated, but threats to body fluid homeostasis were absent. Consequently, the increased PRA elicited by psychological stress is independent of challenges to body fluid homeostasis. During stress exposure, the autonomic nervous system increases sympathetic outflow, resulting in elevated heart rate, blood pressure, and circulating catecholamines (i.e., the fight or flight response). Renin release, the rate-limiting step in the biosynthesis of ANGII, is regulated in part by the sympathetic nervous system. Specifically, increased renal sympathetic nerve activity stimulates $\beta$-adrenergic receptors on juxtaglomerular cells of the kidney to cause the secretion of renin into the circulation (Kopp and DiBona, 1993). In this regard, rats classically conditioned to tail shock or exposed to air jet stress have robust increases in renal sympathetic nerve activity (Randall et al., 1994; Kanbar et al., 2007). Therefore, the elevated ANGII that accompanied restraint stress was likely triggered by augmented sympathetic outflow, which implies that most stress exposures are probably followed by increased circulating ANGII.

In addition to circulating ANGII, several tissues, including brain, synthesize ANGII locally (Bader and Ganten, 2008), and it is possible that centrally derived ANGII mediates stress responding and contributes to the increased $c$-fos mRNA observed in the SFO after restraint. However, peripheral pretreatment with losartan, an AT1R antagonist that is impermeable to the blood-brain barrier, significantly decreased restraint-induced $c$-fos mRNA in the SFO (Bui et al., 1992). These results are consistent with previous studies demonstrating that elevated circulating ANGII is accompanied by increased $c$-fos in the SFO, which can be attenuated or eliminated by systemic pretreatment with losartan (Oldfield and McKinley, 1994; Rowland et al., 1996).Together, the results suggest that blood-borne ANGII activated SFO neurons during stress exposure.

Our tract-tracing studies found that fibers originating in the SFO made direct apposition onto neurons in the PVN that were also activated by restraint. The SFO is a circumventricular organ with strong direct projections to the parvocellular division of the PVN (Miselis, 1981; Swanson and Lind, 1986). The parvocellular PVN contains neurons that project to the brainstem and spinal cord to regulate cardiovascular function (Tucker and Saper, 1985; Shafton et al., 1998), as well as neurons expressing corticotropinreleasing-hormone that control the HPA axis (Herman et al., 2003), and both neuronal phenotypes are activated in response to stress (Ulrich-Lai and Herman, 2009). It is well documented that AT1R in the SFO mediates the cardiovascular responses to systemic ANGII (Mangiapane and Simpson, 1980; Lind et al., 1983; Ku and Li, 2003), and the present findings indicate that SFO projections to the PVN also influence activation of the HPA axis. Therefore, it is likely that the c-fos-positive neurons in the PVN that 
receive projections from the $\mathrm{SFO}$ are involved in the cardiovascular or HPA responses to stress, and the implication is that systemic ANGII is a mediator of both.

Given that SFO fibers make direct apposition onto stressactivated neurons in the PVN, it is reasonable to hypothesize that systemic ANGII excites the HPA axis via this SFO-PVN pathway. Consistent with this, electrophysiological studies indicate that stimulation of the SFO by ANGII elicits activation of medial parvocellular neurons in the PVN and increased circulating ACTH (Ferguson, 1988; Plotsky et al., 1988). Here, we demonstrate that blood-borne ANGII uses the same circuit to drive activation of the HPA axis when animals undergo psychological stress. Specifically, virally mediated inhibition of AT1R binding in the SFO significantly decreased restraint-induced release of ACTH and CORT at 15 and $30 \mathrm{~min}$, respectively. These data, in conjunction with our previously mentioned results, suggest that the connectivity of the SFO subserves the effects of systemic ANGII to influence the neural activity of the PVN and initiate activation of the HPA axis.

Chronic inhibition of AT1R in the SFO also increased the amount of time that rats spent in the open arms of the EPM, indicative of decreased anxiety-like behavior. These results are consistent with those of Saavedra et al. (2006), indicating that long-term treatment with an AT1R antagonist is anxiolytic. It is unclear whether the attenuated HPA responding that we observed contributed to the anxiolytic effects of AT1R knockdown in the SFO, because others have found that behavioral responses to stress are independent of the HPA axis (Koob et al., 1993). As mentioned, the AT1R in the SFO contribute to the cardiovascular effects of ANGII, and it is possible that reduced cardiovascular reactivity to stress may have contributed to the decreased anxietylike behavior observed in our experiments. In this regard, transgenic mice lacking the AT1R have decreased cardiovascular reactivity to aversive stress, and this effect appears to be centrally mediated (Davern et al., 2009). However, the SFO also has angiotensinergic projections to neurons in the DRN that contain serotonin (Lind, 1986; Tanaka et al., 1998). The midbrain serotonin system has been studied extensively for its role in depression and anxiety (for review, see Lowry et al., 2008), and the efferent pathways from the SFO to the DRN may represent a neural circuit by which systemic ANGII can influence mood directly.

While our results implicate the SFO in the control of the HPA and behavioral responses to acute stress, we have not ruled out roles for the area postrema or hindbrain nuclei known to regulate cardiovascular responses to circulating ANGII and repeated stress, respectively (Fink et al., 1987; Bechtold et al., 2009). Although the present study focuses on acute stress responding, exposure to chronic stress is associated with the onset of psychopathology and CVD, and, notably, repeatedly stressed rats have elevated central expression of the AT1R (Castren and Saavedra, 1988; Leong et al., 2002). Correspondingly, humans with polymorphisms in the ACE gene, which elevates ACE activity and promotes the synthesis of ANGII, have increased incidence of psychopathology and HPA dysregulation (Baghai et al., 2006). Thus, it may be that stressful life events and/or genetic polymorphisms may dysregulate the central actions of ANGII, resulting in affective disorder and hypercortisolism. Consequently, further research examining the effect of chronic stress on central angiotensinergic circuits mediating mood, cardiovascular function, and the HPA axis may reveal the mechanism underlying the comorbidity of psychopathology and CVD.

\section{References}

Angunsri R, Sritharathikhun T, Suttirat S, Tencomnao T (2009) Association of angiotensin-converting enzyme gene promoter single nucleotide polymorphisms and haplotype with major depression in a northeastern Thai population. J Renin Angiotensin Aldosterone Syst 10:179-184.

Bader M, Ganten D (2008) Update on tissue renin-angiotensin systems. J Mol Med 86:615-621.

Baghai TC, Schule C, Zwanzger P, Minov C, Zill P, Ella R, Eser D, Oezer S, Bondy B, Rupprecht R (2002) Hypothalamic-pituitary-adrenocortical axis dysregulation in patients with major depression is influenced by the insertion/deletion polymorphism in the angiotensin I-converting enzyme gene. Neurosci Lett 328:299-303.

Baghai TC, Binder EB, Schule C, Salyakina D, Eser D, Lucae S, Zwanzger P, Haberger C, Zill P, Ising M, Deiml T, Uhr M, Illig T, Wichmann HE, Modell S, Nothdurfter C, Holsboer F, Müller-Myhsok B, Möller HJ, Rupprecht R, Bondy B (2006) Polymorphisms in the angiotensin-converting enzyme gene are associated with unipolar depression, ACE activity and hypercortisolism. Mol Psychiatry 11:1003-1015.

Bechtold AG, Patel G, Hochhaus G, Scheuer DA (2009) Chronic blockade of hindbrain glucocorticoid receptors reduces blood pressure responses to novel stress and attenuates adaptation to repeated stress. Am J Physiol Regul Integr Comp Physiol 296:R1445-R1454.

Bui JD, Kimura B, Phillips MI (1992) Losartan potassium, a nonpeptide antagonist of angiotensin II, chronically administered p.o. does not readily cross the blood-brain barrier. Eur J Pharmacol 219:147-151.

Carroll D, Phillips AC, Gale CR, Batty GD (2010) Generalized anxiety and major depressive disorders, their comorbidity and hypertension in middle-aged men. Psychosom Med 72:16-19.

Castren E, Saavedra JM (1988) Repeated stress increases the density of angiotensin II binding sites in rat paraventricular nucleus and subfornical organ. Endocrinology 122:370-372.

Cullinan WE, Herman JP, Battaglia DF, Akil H, Watson SJ (1995) Pattern and time course of immediate early gene expression in rat brain following acute stress. Neuroscience 64:477-505.

Davern PJ, Chen D, Head GA, Chavez CA, Walther T, Mayorov DN (2009) Role of angiotensin II Type 1A receptors in cardiovascular reactivity and neuronal activation after aversive stress in mice. Hypertension 54:1262-1268.

Dragunow M, Faull R (1989) The use of c-fos as a metabolic marker in neuronal pathway tracing. J Neurosci Methods 29:261-265.

Ferguson AV (1988) Systemic angiotensin acts at the subfornical organ to control the activity of paraventricular nucleus neurons with identified projections to the median eminence. Neuroendocrinology 47:489-497.

Fink GD, Bruner CA, Mangiapane ML (1987) Area postrema is critical for angiotensin-induced hypertension in rats. Hypertension 9:355-361.

Garcia-Vera MP, Sanz J, Espinosa R, Fortún M, Magán I (2010) Differences in emotional personality traits and stress between sustained hypertension and normotension. Hypertens Res 33:203-208.

Herman JP, Figueiredo H, Mueller NK, Ulrich-Lai Y, Ostrander MM, Choi DC, Cullinan WE (2003) Central mechanisms of stress integration: hierarchical circuitry controlling hypothalamo-pituitary-adrenocortical responsiveness. Front Neuroendocrinol 24:151-180.

Holsboer F, Barden N (1996) Antidepressants and hypothalamic-pituitaryadrenocortical regulation. Endocr Rev 17:187-205.

Kanbar R, Oréa V, Barrès C, Julien C (2007) Baroreflex control of renal sympathetic nerve activity during air-jet stress in rats. Am J Physiol Regul Integr Comp Physiol 292:R362-R367.

Kawano H, Masuko S (2010) Region-specific projections from the subfornical organ to the paraventricular hypothalamic nucleus in the rat. Neuroscience 169:1227-1234

Koob GF, Heinrichs SC, Pich EM, Menzaghi F, Baldwin H, Miczek K, Britton KT (1993) The role of corticotropin-releasing factor in behavioural responses to stress. Ciba Found Symp 172:277-295.

Kopp UC, DiBona GF (1993) Neural regulation of renin secretion. Semin Nephrol 13:543-551.

Krause EG, Sakai RR (2007) Richter and sodium appetite: from adrenalectomy to molecular biology. Appetite 49:353-367.

Krause EG, Curtis KS, Stincic TL, Markle JP, Contreras RJ (2006) Oestrogen and weight loss decrease isoproterenol-induced Fos immunoreactivity and angiotensin type 1 mRNA in the subfornical organ of female rats. J Physiol 573:251-262.

Krause EG, Melhorn SJ, Davis JF, Scott KA, Ma LY, de Kloet AD, Benoit SC, 
Woods SC, Sakai RR (2008) Angiotensin type 1 receptors in the subfornical organ mediate the drinking and hypothalamic-pituitary-adrenal response to systemic isoproterenol. Endocrinology 149:6416-6424.

Ku YH, Li YH (2003) Subfornical organ-angiotensin II pressor system takes part in pressor response of emotional circuit. Peptides 24:1063-1067.

Leong DS, Terrón JA, Falcón-Neri A, Armando I, Ito T, Jöhren O, Tonelli LH, Hoe KL, Saavedra JM (2002) Restraint stress modulates brain, pituitary and adrenal expression of angiotensin II AT(1A), AT(1B) and AT(2) receptors. Neuroendocrinology 75:227-240.

Li Z, Ferguson AV (1993) Subfornical organ efferents to paraventricular nucleus utilize angiotensin as a neurotransmitter. Am J Physiol 265: R302-R309.

Lind RW (1986) Bi-directional, chemically specified neural connections between the subfornical organ and the midbrain raphe system. Brain Res 384:250-261.

Lind RW, Ohman LE, Lansing MB, Johnson AK (1983) Transection of subfornical organ neural connections diminishes the pressor response to intravenously infused angiotensin II. Brain Res 275:361-364.

Lowry CA, Hale MW, Evans AK, Heerkens J, Staub DR, Gasser PJ, Shekhar A (2008) Serotonergic systems, anxiety, and affective disorder: focus on the dorsomedial part of the dorsal raphe nucleus. Ann NY Acad Sci 1148:86-94.

Mangiapane ML, Simpson JB (1980) Subfornical organ: forebrain site of pressor and dipsogenic action of angiotensin II. Am J Physiol 239: R382-R389.

McKinley MJ, McAllen RM, Davern P, Giles ME, Penschow J, Sunn N, Uschakov A, Oldfield BJ (2003) The sensory circumventricular organs of the mammalian brain. Adv Anat Embryol Cell Biol 172:1-222.

Miselis RR (1981) The efferent projections of the subfornical organ of the rat: a circumventricular organ within a neural network subserving water balance. Brain Res 230:1-23.

Oldfield BJ, McKinley MJ (1994) Distribution of Fos in rat brain resulting from endogenously-generated angiotensin II. Kidney Int 46:1567-1569.

Pavlatou MG, Mastorakos G, Lekakis I, Liatis S, Vamvakou G, Zoumakis E, Papassotiriou I, Rabavilas AD, Katsilambros N, Chrousos GP (2008) Chronic administration of an angiotensin II receptor antagonist resets the hypothalamic-pituitary-adrenal (HPA) axis and improves the affect of patients with diabetes mellitus type 2: preliminary results. Stress 11: $62-72$.

Paxinos G, Watson C (1997) The rat brain in stereo-taxic coordinates. San Diego: Academic.

Plotsky PM, Sutton SW, Bruhn TO, Ferguson AV (1988) Analysis of the role of angiotensin II in mediation of adrenocorticotropin secretion. Endocrinology 122:538-545.

Randall DC, Brown DR, Brown LV, Kilgore JM (1994) Sympathetic nervous activity and arterial blood pressure control in conscious rat during rest and behavioral stress. Am J Physiol 267:R1241-R1249.

Rigat B, Hubert C, Alhenc-Gelas F, Cambien F, Corvol P, Soubrier F (1990) An insertion/deletion polymorphism in the angiotensin I-converting enzyme gene accounting for half the variance of serum enzyme levels. J Clin Invest 86:1343-1346.

Rowland NE, Morien A, Fregly MJ (1996) Losartan inhibition of angiotensin-related drinking and Fos immunoreactivity in hypertensive and hypotensive contexts. Brain Res 742:253-259.

Saavedra JM, Armando I, Bregonzio C, Juorio A, Macova M, Pavel J, SanchezLemus E (2006) A centrally acting, anxiolytic angiotensin II AT1 receptor antagonist prevents the isolation stress-induced decrease in cortical CRF1 receptor and benzodiazepine binding. Neuropsychopharmacology 31:1123-1134.

Shafton AD, Ryan A, Badoer E (1998) Neurons in the hypothalamic paraventricular nucleus send collaterals to the spinal cord and to the rostral ventrolateral medulla in the rat. Brain Res 801:239-243.

Solomon MB, Jones K, Packard BA, Herman JP (2010) The medial amygdala modulates body weight but not neuroendocrine responses to chronic stress. J Neuroendocrinol 22:13-23.

Sowden GL, Huffman JC (2009) The impact of mental illness on cardiac outcomes: a review for the cardiologist. Int J Cardiol 132:30-37.

Stein DJ, Scott K, Haro Abad JM, Aguilar-Gaxiola S, Alonso J, Angermeyer M, Demytteneare K, de Girolamo G, Iwata N, Posada-Villa J, Kovess V, Lara C, Ormel J, Kessler RC, Von Korff M (2010) Early childhood adversity and later hypertension: data from the World Mental Health Survey. Ann Clin Psychiatry 22:19-28.

Swanson LW, Lind RW (1986) Neural projections subserving the initiation of a specific motivated behavior in the rat: new projections from the subfornical organ. Brain Res 379:399-403.

Tanaka J, Ushigome A, Hori K, Nomura M (1998) Responses of raphe nucleus projecting subfornical organ neurons to angiotensin II in rats. Brain Res Bull 45:315-318.

Tucker DC, Saper CB (1985) Specificity of spinal projections from hypothalamic and brainstem areas which innervate sympathetic preganglionic neurons. Brain Res 360:159-164.

Ulrich-Lai YM, Herman JP (2009) Neural regulation of endocrine and autonomic stress responses. Nat Rev Neurosci 10:397-409. 